\title{
A NORMALISTA JULIA WANDERLEY: DECISÃO, SENSIBILIDADE E NECESSIDADES SOCIAIS
}

\author{
NORMALISTA JULIA WANDERLEY: DECISIÓN, SENSIBILIDAD Y NECESIDADES \\ SOCIALES
}

NORMALIST JULIA WANDERLEY: DECISION, SENSIVITY AND SOCIAL NEEDS

\author{
Marcia Marlene STENTZLER ${ }^{1}$ \\ Elaine Maestre Polido de ARAÚJO² \\ Luiz Felipe MARQUES ${ }^{3}$
}

RESUMO: O objetivo deste artigo é resgatar aspectos da trajetória acadêmico-social de Julia Wanderley, a primeira mulher paranaense a frequentar e concluir o curso normal no Século XIX. Para tanto, destacaremos o contexto educacional formativo e o processo de inserção da figura feminina nos espaços de poder, com ênfase na formação de professores nesta província, posteriormente, estado do Paraná. A luta de Julia Wanderley marca a luta da mulher pelo direito à escolarização, contra objeções e preconceitos, conquistando o direito a frequentar e se formar em uma escola normal. Mulheres como ela avançaram no combate ao conservadorismo social e limitações impostas ao direito e à profissionalização feminina. A iniciativa de Julia Wanderley trouxe mudanças para o cenário educacional paranaense, incentivando outras mulheres a buscar a formação na escola normal e se tornarem professoras normalistas, socialmente respeitadas e reconhecidas junto às comunidades onde atuavam.

PALAVRAS-CHAVE: Docência. Escolas. Mulher.

RESUMEN: El propósito de este artículo es rescatar aspectos de la trayectoria académicosocial de Julia Wanderley, la primera mujer de Paraná en asistir y completar el curso normal en el siglo XIX. Para ello, destacaremos el contexto educativo y el proceso de inserción de la figura femenina en los espacios de poder, con énfasis en la formación de docentes en esta provincia, posteriormente, en el estado de Paraná. La lucha de Julia Wanderley marca la lucha de la mujer por el derecho a la escuela, contra las objeciones y prejuicios, ganándose el derecho de asistir y graduarse de una escuela normal. Mujeres como ella han avanzado en la lucha contra el conservadurismo social y las limitaciones impuestas a los derechos y la profesionalización de las mujeres. La iniciativa de Julia Wanderley trajo cambios al escenario educativo en Paraná, alentando a otras mujeres a buscar capacitación en la

\footnotetext{
${ }^{1}$ Universidade Estadual do Paraná (UNESPAR), Paranavaí - PR - Brasil. Professora Adjunta no Curso de Pedagogia e Docente no Programa de Pós-graduação em Ensino: Formação Docente Interdisciplinar. Doutorado em Educação (UFPR). ORCID: https://orcid.org/0000-0002-9634-9148. E-mail: mmstentzler@gmail.com

${ }^{2}$ Universidade Estadual do Paraná (UNESPAR), Paranavaí - PR - Brasil. Mestranda no Programa de Pósgraduação em Ensino: Formação Docente Interdisciplinar. ORCID: https://orcid.org/0000-0002-8574-2470. Email: elainepolido@hotmail.com

${ }^{3}$ Universidade Estadual do Paraná (UNESPAR), Paranavaí - PR - Brasil. Mestrando no Programa de Pósgraduação em Ensino: Formação Docente Interdisciplinar. ORCID: https://orcid.org/0000-0002-5346-0639. Email: luizfelipe-12360@hotmail.com
} 
escuela normal y convertirse en maestras normalistas, socialmente respetadas y reconocidas en las comunidades donde trabajaban.

PALABRAS CLAVE: Enseñando. Escuelas. Mujer.

ABSTRACT: The purpose of this article is to rescue aspects of the academic-social trajectory of Julia Wanderley, the first woman from Paraná to attend and complete the normal course in the 19th century. To this end, we will highlight the educational formative context and the process of insertion of the female figure in the spaces of power, with emphasis on the formation of teachers in this province, later, the state of Paraná. Julia Wanderley's struggle marks the woman's struggle for the right to schooling, against objections and prejudices, earning the right to attend and graduate from a normal school. Women like her have advanced in the fight against social conservatism and limitations imposed on women's rights and professionalization. Julia Wanderley's initiative brought changes to the educational scenario in Paraná, encouraging other women to seek formation in normal school and become normalist teachers, socially respected and recognized in the communities where they worked.

KEYWORDS: Teaching. Schools. Woman.

\section{Introdução}

Com a ampliação do ensino público no Brasil surge a necessidade de se formar e capacitar professores para lecionar nas escolas primárias, as escolas de primeiras letras. Para assumir tal atribuição foram criadas as escolas normais, introduzidas aqui no século XIX, mais precisamente no ano de 1835 (BRASIL, 1835), perdurando por mais de um século, até a publicação da Lei de Diretrizes e Bases da Educação Nacional/LDB n ${ }^{0}$ 5.692/71 (BRASIL, 1971), quando foram extintas (MARTINS, 2009).

As escolas normais passaram por inúmeras dificuldades para se firmar no cenário nacional (MIGUEL, 2008). No estado do Paraná, essa modalidade de escola foi criada pela Lei $n^{\circ}$ 238/1870 e sancionada pelo Presidente da Província do Paraná, Antonio Luiz Affonso de Carvalho (MIGUEL, 2008; MIGUEL; MARTIN, 2004). De acordo com o Artigo nono da referida Lei, “o provimento definitivo das escolas de instrução primária só poderá ser obtido de agora em diante por normalistas" (PARANÁ, 1870, p. 170). Contudo, embora constasse a proibição de professores sem a formação normalista ter o provimento definitivo, os professores leigos foram imprescindíveis para o funcionamento de escolas primárias, inclusive no século XX, em localidades no interior do Estado do Paraná.

Ao longo de sua existência, as escolas normais formaram moças e rapazes. Porém, para as mulheres, o currículo sofreu modificações, agregando ao ensino os trabalhos manuais 
(MARTINS, 2009). Inicialmente essas instituições formavam apenas homens, visto que no momento de sua criação, a ideia presente na sociedade aristocrática e conservadora era a de que não cabia bem para a mulher o papel de professora, assim como o de muitas outras profissões. Isso fazia com que as mulheres ficassem restritas ao trabalho doméstico e aos cuidados para com o marido e os filhos, ou seja, deveriam permanecer em seus lares cuidando da família e protegidas da exposição que um trabalho poderia causar à sua imagem ou à imagem da figura masculina responsável por ela (ALMEIDA, 2004).

No entanto, ao longo dos anos, essa visão preconceituosa de não oportunizar às mulheres a formação de professora foi sendo modificada. Em 1882, o relatório apresentado ao presidente da província Carlos Augusto de Carvalho, por Moysés Marcondes, diretor-geral de instrução pública da província do Paraná, já demonstrava mudança. Ele via com bons olhos a formação de mulheres para a função de professoras das escolas primárias e recomendava ao presidente da província que estimulasse o ingresso de moças na escola normal paranaense. Marcondes considerava que as mulheres eram, de forma nata,

[...] mais bem-dotadas que os homens para as funções do ensino primário. Esta verdade é intuitiva desde que considerarmos que, para ser mãe, a mulher deve reconhecer todos os recantos do coração e do espírito da criança (PARANÁ, 1882, p. 6-7).

A ideia do cuidado associado ao ato de instruir, ensinando as primeiras letras às crianças, começou a ser considerada uma tarefa adequada às mulheres.

Na década de 1870, período marcado pelo nascimento da escola normal no Paraná, mais precisamente em 1874, nascia aquela que marcaria definitivamente a formação de professores normalistas no Paraná, tratava-se de Julia Wanderley (1874-1918). Esta paranaense ficou conhecida pela sua trajetória de luta e persistência, conquistando no ano de 1890 o direito de frequentar as aulas do curso oferecido pela Escola Normal do Paraná, até então frequentada somente por rapazes. As últimas décadas do século XIX e o início do século XX no Brasil, trouxeram à tona reivindicações do público feminino pela oferta do curso normal às mulheres.

Neste trabalho, temos como objetivo resgatar aspectos da trajetória acadêmico-social de Julia Wanderley, a primeira mulher paranaense a frequentar e concluir o curso normal no Século XIX. O tempo histórico possibilitou que a persistência de Julia rendesse a ela o direito a estudar na escola normal. Sua atitude encorajou outras mulheres a lutarem pelo seu espaço e a ingressarem no curso para formação de normalistas. Isso foi determinante para que, 
atualmente, a docência na Educação Infantil e nos anos iniciais do Ensino Fundamental seja exercido predominantemente por mulheres.

Em meio a um período de exclusão das mulheres, as quais deveriam ser submissas aos homens da família (as solteiras aos pais e as casadas aos maridos) e diante da trajetória conturbada da escola normal no Brasil e no Paraná, discutiremos como a mulher paranaense conquistou o seu espaço na sociedade e no ofício docente. As mudanças na sociedade brasileira foram determinantes para a conscientização de gênero na esfera educacional e a expansão do ensino público no Brasil. Trabalhamos em uma perspectiva sócio-histórica, abordando aspectos relevantes na mudança do comportamento da sociedade, os quais impulsionaram a feminização do magistério.

O trabalho se organiza a partir da trajetória político-social das escolas normais brasileiras, com destaque para as instituições do Paraná. Na sequência, situaremos o contexto socioeducacional em que Júlia Wanderley se profissionalizou e atuou, a posição social exercida pelas mulheres no final século XIX e início do século XX, e a consolidação da figura feminina na prática docente.

\section{Formação de professores para escolas primárias no Paraná}

O ofício de professor, na sociedade moderna, iniciou-se como uma atividade secundária e informal. Inicialmente exercida por religiosos e leigos de forma não especializada (NÓVOA, 1995). No Brasil colônia, a atuação educacional dos jesuítas tinha como principal objetivo a evangelização e a propagação da fé católica (ROMANELLI, 2014). Contudo, com a passagem do período colonial para o moderno ${ }^{4}$, a escolarização assumiu papel central na consolidação dos estados nacionais. Regulado pelo estado, o processo de escolarização primária exigiu um novo perfil de professor formado em escolas específicas para esse fim, as escolas normais.

Para Martins (2009, p. 174), com a institucionalização da educação,

[...] as representações veiculadas e fortalecidas no ambiente escolar criam identidades fundamentais para o reconhecimento profissional do professor, como servem para a construção de posturas do ser estudante.

As escolas normais propiciaram a profissionalização da docência, particularmente nas escolas primárias do país, preparando "aquele que iria trabalhar diretamente com o povo"

\footnotetext{
${ }^{4}$ As origens do Estado moderno estão calcadas em dois períodos históricos: a revolução industrial inglesa e a
} revolução francesa. A ideia de moderno se contrapõe ao antigo, ultrapassado.

RPGE- Revista on line de Política e Gestão Educacional, Araraquara, v. 25, n. 1, p. 149-167, jan./abr. $2021 . \quad$ e-ISSN:1519-9029 
(MIGUEL, 2008, p. 3). Ainda, conforme a autora citada, "os dirigentes buscavam na formação do professor o auxílio para a melhoria da sociedade", papel atribuído à Escola Normal desde o seu nascimento (MIGUEL, 2008, p. 3).

No período imperial, a primeira escola normal foi criada no município de Niterói, na Província do Rio de Janeiro, por meio do Decreto $n^{\circ} 10 / 1835$. Essa lei estabeleceu para qual fim se destinava a criação da escola normal, quais conteúdos deveriam ser ministrados, as exigências impostas ao ingresso dos interessados e as providências para iniciar os estudos na instituição. Embora estabelecesse a criação da Escola Normal na Província, a lei impunha como condição para o seu funcionamento que houvesse mais de dez matrículas efetuadas (BRASIL, 1835). Quanto à finalidade da Escola Normal, em seu primeiro artigo, o documento determina que:

Haverá na Capital da Província do Rio de Janeiro uma Escola Normal para nela se habilitarem as pessoas, que se destinarem ao magistério de instrução primária, e os Professores atualmente existentes, que não tiverem adquirido a necessária instrução nas Escolas de Ensino na conformidade da Lei de quinze de Outubro de mil oitocentos e vinte sete, Artigo quinto (BRASIL, $1835)$.

A primeira Escola Normal do Brasil durou pouco tempo (1835-1851) devido à instabilidade pela qual as escolas normais passaram no início de sua existência, a qual se atribui, segundo Miguel (2008) e Castanha (2008), pela deficiência de seu modelo pedagógico e pela falta de interesse das pessoas em se tornarem professores. A partir de sua criação, a propagação desse modelo de escola foi ocorrendo de forma gradativa por outros locais do império. Citamos o exemplo da Escola Normal de São Paulo, criada em 1846. Na década de 1870, foram criadas escolas, na região de Minas Gerais, Espírito Santo, Rio Grande do Norte e Paraná (MARTINS, 2009; STENTZLER, 2018).

Castanha (2008) e Miguel (2008) explicitam que a Escola Normal no Brasil passou por reformulações devido às constantes dúvidas por parte dos governantes, em relação à necessidade de sua existência e ao tipo de trabalho que estava sendo desenvolvido nela, pois possuía um currículo fragilizado que ia um pouco além dos conteúdos da escola primária. Esses questionamentos foram permeados pela baixa procura de candidatos para nela ingressar e "até próximo ao final do Império a baixa frequência se deu, principalmente pelo pouco prestígio que os professores e a própria instrução pública gozavam naquele período" (CASTANHA, 2008, p. 30). A maior parte da população não via necessidade de frequentar escolas de primeiras letras e, para muitos, parecia ser desnecessária a formação de professores. Segundo Romanelli (2014), em 1888 havia apenas 250 mil alunos matriculados 
em escolas primárias dentre uma população de mais de 14 milhões de habitantes no território brasileiro.

Com isso, o modelo de formação ofertado aos professores nas escolas normais mostrava-se frágil. Gondra (2018, p. 38) explica que em 1854 foi instituído o Regulamento da Instrução Primária e Secundária do Município da Corte, estabelecido pelo Decreto $\mathrm{n}^{\mathrm{o}}$ 1.331A, o qual definia o modelo de instrução propiciada aos futuros professores no Município Neutro $^{5}$, pautado na prática. Para isso, foi estabelecida a classe dos professores adjuntos, que eram "exercitados na arte de ensinar", conforme o autor. Bastaria a eles ter um conhecimento básico dos conteúdos, saber aplicar de certa forma o método usado nas escolas e, de maior importância, deveriam privilegiar a formação da moral em seus alunos. O Decreto determinava:

\begin{abstract}
Art. 34. Haverá uma classe de professores adjuntos, cujo número será marcado por um Decreto, ouvidos o Inspector Geral e o Conselho Diretor. Art. 35. A classe dos professores adjuntos será formada dos alunos das escolas públicas, maiores de 12 anos de idade, dados por prontos com distinção nos exames anuais, que tiverem tido bom procedimento, e mostrado propensão para o magistério (RIO DE JANEIRO, 1854).
\end{abstract}

O dispositivo também demonstra que a boa conduta e moral eram essenciais ao exercício da profisssão. Só estariam aptos a exercer a docência aqueles que comprovassem sua moralidade, por meio de documento que deveria ser apresentado ao Inspetor Geral (RIO DE JANEIRO, 1854). O professor deveria bem representar os interesses do Império, propagando os bons costumes e os valores da época, além de incentivar o respeito às decisões dos governantes. Tais aspectos funcionariam como uma forma de controlar a população.

A partir de 1870, podemos observar o início de um enfoque diferenciado na educação brasileira. Começou a ocorrer a exigência de prédios próprios para as escolas e se iniciou o reconhecimento da importância da Escola Normal para a formação de professores qualificados. A década marca, também, a criação da Escola Normal na então província do Paraná, ocorrida em 1870, bem como o estabelecimento da Escola Normal da Côrte em 1880, para ambos os sexos (MARTINS, 2009; GONDRA, 2018).

Com a Proclamação da República brasileira, em 15 de novembro de 1889, a alfabetização e o acesso à educação tornaram-se uma necessidade social, implícita ao regime republicano. Associado a mudanças contundentes na organização do trabalho decorrentes do

${ }^{5}$ Foi instituído pelo Ato Adicional de 1834, separando o município do Rio de Janeiro da província do Rio de Janeiro na época do Brasil Império. Com a proclamação da República em 1889, o Município Neutro transformou-se em Distrito Federal (LINHARES, 2020).

RPGE- Revista on line de Política e Gestão Educacional, Araraquara, v. 25, n. 1, p. 149-167, jan./abr. $2021 . \quad$ e-ISSN:1519-9029 
processo de urbanização e industrialização, os trabalhadores se viram obrigados a se preocupar com a escolarização, a fim de se inserir no mercado de trabalho (MIGUEL, 2008). Nesse contexto, as escolas necessitavam de professores capacitados para prover a instrução geral para a infância, dentro dos princípios da escola moderna.

\begin{abstract}
A busca de um profissional da educação de acordo com os novos princípios de urbanidade, um civilizador, estava presente nas discussões e reformas educacionais do final do século XIX e início do século XX. Era preciso formar um novo tipo de educador, num 'locus' específico, a Escola Normal deveria possuir instalações apropriadas à sua missão, de acordo com os princípios morais e científicos que pudessem 'conformar' o homem moderno e civilizado (MARTINS, 2009, p. 180).
\end{abstract}

Nessa conjuntura, as escolas normais passaram a ser mais procuradas, com uma mudança significativa em relação aos seus candidatos, visto que muitas eram mulheres (CASTANHA, 2008). Essa foi uma marca da transição entre o modelo educacional no século XIX e XX. Ser professor passou a ser, gradativamente, uma profissão tipicamente feminina. Essa mudança de perspectiva do mundo do trabalho esteve associada a questões econômicas e à ideia de o magistério ser considerado uma extensão dos cuidados maternais (HAHNER, 2011). E diante dessa transformação, a expansão das escolas normais foi ocorrendo gradualmente pelo Brasil.
A Escola Normal aos poucos se configurou como instituição necessária para formar tecnicamente o professor. Com a criação dos grupos escolares, da seriação do ensino, do agrupamento dos alunos em classes segundo o seu grau de adiantamento e o surgimento da figura do diretor da escola, cada vez mais se fez indispensável qualificar o professor (MIGUEL, 2008, p. 12).

As mudanças também chegaram ao estado do Paraná. Em 31 de agosto de 1895, o Secretário dos Negócios do Interior, Justiça e Instrução Pública, Caetano Alberto Munhoz, apresentou ao governador Francisco Xavier da Silva um relatório dizendo que no ano anterior a escola normal paranaense tinha sido frequentada por apenas seis alunos, mas que no presente ano a quantidade de alunos havia aumentado para 14, sendo 13 mulheres e um homem. Tendo em vista que nesse período a Escola Normal já aceitava a matrícula de homens e mulheres, o secretário aproveitou para solicitar a implantação de uma rigorosa fiscalização entre os alunos normalistas, com o intuito de evitar atitudes promíscuas e de falta de respeito que poderiam prejudicar a imagem da escola (PARANÁ, 1895). Aos poucos, a Escola Normal paranaense passou a ser mais procurada.

De acordo com Oliveira (2001), outras transformações importantes ocorreram nas escolas normais do Paraná no início do século XX, como a reorganização do sistema 
educacional, direcionando esforços para ampliar a formação de professores e o investimento na construção de um prédio específico para abrigar a Escola Normal em Curitiba, inaugurado em setembro de 1922. Tal prédio ficou conhecido como Palácio da Instrução (MIGUEL, 2008; CORREIA, 2013), marcando a história da Escola Normal em Curitiba. Nessa década, mais duas escolas normais foram criadas no Paraná. No entanto, ambas eram escolas normais de caráter primário: a primeira delas foi inaugurada na cidade de Ponta Grossa (1924) e a outra na cidade de Paranaguá (1927) .

A reforma da Escola Normal realizada no estado por Lysímaco Ferreira da Costa $^{7} \mathrm{em}$ 1922, segundo Miguel (2008), concentrou-se em moldar os valores da população, propagando ideários que tratavam da higiene (cuidados básicos de saúde), da valorização cívica (nacionalismo) e da moral (atitudes alinhadas com a cultura do período). Para tanto, o professor deveria ser obediente ao estado. Ele enxergava esse perfil de obediência ao estado mais presente nas jovens egressas da Escola Normal, as quais passaram a lecionar no lugar dos formandos do Ginásio Paranaense ${ }^{8}$. De acordo com a autora citada, apesar de possuir cunho tradicionalista, as mudanças trouxeram avanços significativos para a educação paranaense, institucionalizando a formação de professores no estado.

\section{Da infância ao ingresso de Julia Wanderley no magistério paranaense}

Desde o período colonial (1530-1822) até a segunda metade do século XVIII (17501799), a arte de ensinar era vista como uma prática eminentemente masculina. A sociedade brasileira não cogitava a possibilidade de inserir mulheres nesse ramo, uma vez que as obrigações domésticas e maternais já ocupavam o seu tempo. No início do século XIX, isso começa a mudar gradativamente. Nesse período, as moças "estudavam em casa, por conta própria ou com preceptores" (ARAUJO, 2010, p. 27) e logo depois poderiam prestar os “exames vagos" para obter o diploma de normalista.

As transformações que se avizinhavam estavam correlacionadas com o processo de reorganização da sociedade, mudanças decorrentes da urbanização e a presença de outros

${ }^{6}$ A escolha dessas duas cidades deu-se pelo fato de ter grande concentração de população para serem centros formadores de professores. Pela sua localização, essas cidades irradiariam a modernização para as localidades de sua região de abrangência. Um outro aspecto também considerado foi a preocupação em nacionalizar essas regiões, propagando valores nacionais, com destaque para os Campos Gerais, onde se localiza Ponta Grossa. No período, possuía alta concentração de imigrantes provenientes de vários países (CORREIA, 2013).

${ }^{7}$ Foi diretor do Ginásio Paranaense e Escola Normal. Realizou a reforma do Ensino Normal em 1922, em que foi redator das Bases Educativas da Escola Normal. Para tal reforma, foi influenciado pela pedagogia de Herbart, considerada uma pedagogia tradicional (MIGUEL, 2008).

${ }^{8}$ Atuou como o principal estabelecimento regulador do curso secundário regular no Paraná (RANZI; SILVA, 2009).

RPGE- Revista on line de Política e Gestão Educacional, Araraquara, v. 25, n. 1, p. 149-167, jan./abr. 2021. e-ISSN:1519-9029 
atores sociais, como os imigrantes, que traziam experiências educacionais de seus países de origem. Louro (1997, p. 95, grifos do autor) relata que, naquele contexto, o magistério passa a ser uma "atividade permitida e, após muitas polêmicas, indicada para mulheres". O magistério se feminiza, transforma-se para receber as estudantes e, em 1870, houve a abertura de escolas normais para o público feminino. Todavia, foram fechadas na mesma década e reabertas na seguinte, logo a após a reforma de Leôncio de Carvalho em 1879, como escolas mistas (HAHNER, 2011).

Nessa mesma década, mais especificamente no dia 26 de agosto de 1874, nascia na cidade de Ponta Grossa, então Província do Paraná ${ }^{\text {, }}$ uma menina que mais tarde protagonizaria mudanças quanto ao ingresso da mulher na Escola Normal de Curitiba. Mulher, professora e paranaense, Julia Augusta de Souza Wanderley viveu entre o século XIX e XX. Julia ingressou na Escola Normal de Curitiba em 1890 e se formou professora normalista em novembro de 1892. No ano seguinte, "tornou-se a primeira professora normalista e foi nomeada pelo governo estadual à $9^{\circ}$ cadeira da capital" (ARAUJO, 2010, p. 23). Anos mais tarde, a normalista passou a exercer o cargo de diretora na Escola Tiradentes.

A educadora é "rememorada no Paraná como a primeira mulher a se matricular na Escola Normal de Curitiba" (ARAUJO, 2010, p. 27). A biografada também é considerada a primeira mulher a frequentar, presencialmente, um curso normal. O ingresso de Julia Wanderley na Escola Normal de Curitiba oportunizou que outras mulheres pudessem ingressar no curso normal nos anos seguintes, aumentando paulatinamente a presença delas no curso normal.

A representatividade e a memória construída em torno de Julia Wanderley oportunizaram que a sociedade paranaense mitificasse a imagem dessa normalista com o passar dos anos, pelo seu protagonismo e decisão em ser professora normalista. Seu nome hoje é lembrado em bibliotecas e escolas, entre outros. Tal ação é explicada pelo conceito de memória. O historiador francês, Jacques Le Goff define memória como "um elemento essencial do que se costuma chamar identidade, individual e coletiva, cuja busca é uma das atividades fundamentais dos indivíduos e das sociedades" (LE GOFF, 1992, p. 476). Aqui, analisamos a imagem da normalista a partir da identidade coletiva, tendo como ponto de partida o princípio de que:

${ }^{9}$ Região localizada na província do Paraná. Silvete Aparecida Crippa de Araujo define a província do Paraná como sendo "uma província ainda jovem, instaurada em 19 de dezembro de 1853, que buscava se firmar no cenário político e econômico do Brasil Imperial". (ARAUJO, 2010, p. 27). 
[...] a memória coletiva é a recordação ou o conjunto de recordações, conscientes ou não, de uma experiência vivida e/ou mitificada por uma comunidade viva de cuja identidade faz parte integrante o sentimento do passado (NORA, 1990, p. 451).

Essa construção é sócio-histórica. Como tal, a memória necessita ser ressignificada e preservada. Segundo Almeida (2004), no século XIX e início do século XX, homens e mulheres possuíam objetivos diferentes para ingressarem nas escolas normais. A eles e elas, a sociedade depositava expectativas diferentes para a educação:

$\mathrm{O}$ fato de não terem amplo acesso às demais profissões fez do magistério a opção mais adequada para o sexo feminino, o que foi reforçado pelos atributos de missão e vocação, além da continuidade do trabalho do lar. Mantinha-se, pois, a ordem social vigente, e as mulheres teriam uma escola que fornecia um diploma que lhes permitiria sustentar-se em caso de necessidade (ALMEIDA; BOSCHETTI, 2012, p. 230).

Logo, a opção de estudar em uma escola normal foi bem vista pela elite paranaense, uma vez que as moças dessas famílias receberiam uma boa educação, mesmo não exercendo a profissão docente. Além da formação de normalista, as jovens também seriam preparadas para o matrimônio com moços de famílias bem posicionadas socialmente e exerceriam suas funções de esposa e mãe com excelência.

De acordo com pesquisa de Araujo (2010), após concluir o curso normal em 1892, Julia Wanderley casou-se com o escultor gaúcho, Frederico Petrich, em 1895. Após o casamento, Julia sofreu pelo menos um aborto e optou por não gerar filhos. Tal renúncia não quer dizer que a protagonista tenha abdicado da maternidade, pelo contrário, o casal Petrich adotou o sobrinho Julio Wanderley da Costa Petrich, e Julia tornou-se mãe nas salas de aula, uma vez que considerava suas alunas como que filhas. A personagem mitificada na historiografia paranaense foi mãe de inúmeros filhos e filhas intelectuais, sem ao menos ter gerado um em seu ventre.

Podemos compreender mais profundamente a trajetória de Julia com a educação voltando alguns anos no tempo. Era 1877, quando a família de Julia Wanderley ${ }^{10}$, incluindo seus avós maternos, deixou a cidade de Ponta Grossa, se mudando para a capital paranaense, em específico para a região denominada Cajuru, localidade de pouco prestígio na época e "distante do centro da cidade" (SOUSA, 2013, p. 21). Dois anos mais tarde, a família decidiu mudar para o centro da cidade, "onde residiam as camadas médias e a elite local" (SOUSA,

${ }^{10}$ A família de Julia Wanderley era composta pelo pai, Afonso Guilhermino Wanderley, a mãe, Laurinda de Souza Wanderley, a filha primogênita do casal, Julia Augusta de Souza Wanderley, e "mais oito filhos" (SOUSA, 2013, p. 22). 
2013, p. 21). Ao se mudarem para a região central de Curitiba, o pai, comerciante em ascensão, passou a frequentar os círculos republicanos e a tecer relações com a elite local.

Perto de completar sete anos de idade, Julia Wanderley iniciou a sua vida estudantil. Inicialmente, a jovem estudou com professores particulares, como por exemplo, Arminda Couto (1881) e Iria Muricy (1884). No mesmo ano em que foi aluna da professora Iria Muricy, Julia Wanderley passou a estudar na Escola Oliveira Bello. No ano seguinte, "matricula-se no Collegio Coritibano, escola muito bem-conceituada, dirigida pelo professor Nivaldo Braga" (SOUSA, 2013, p. 22). Em 1886 segue para o Colégio Saldanha e, no mesmo ano, é transferida para o Colégio Santa Luiza. Dois anos depois, Julia Wanderley estudou no Colégio Nossa Senhora da Glória e, em 1889, foi aluna do professor Justiniano de Melo e Silva e no ano seguinte de Francisco Guimarães. Nesse mesmo ano, frequentou o colégio do professor Miguel Scheleder e "prestou exames das matérias constitutivas do $1^{\mathrm{o}}$ ano do Curso Normal de Português, Coreografia e História do Brasil" (SOUSA, 2013, p. 32). Em 1891, Julia cursou duas disciplinas no curso Normal, Francês e Retórica Poética.

Nilvan Laurindo Sousa (2013) aponta que Julia Wanderley recebeu uma educação de qualidade. $\mathrm{Na}$ época, Julia foi aluna de professores e escolas particulares de prestígio em Curitiba. Nas instituições de ensino, a protagonista se relacionou com figuras importantes para a história regional, a saber: Sebastião Paraná, Luiza Candido Saldanha, Romário Martins, Ermelino de Leão, João David Perneta e Artur Martins Franco. A pesquisadora acrescentou ainda que a relação desempenhada entre ela e os nomes supracitados da elite local foi "fundamental para a materialização do desempenho profissional e intelectual" de Julia (SOUSA, 2013, p. 24).

Após a conclusão da instrução primária, cursou as matérias constitutivas do primeiro ano do curso normal da instituição curitibana e mais duas disciplinas não-obrigatórias. Em setembro de 1890, reivindicou, junto ao Estado do Paraná, o direito de ingressar na Escola Normal. Em novembro daquele ano realizou a etapa preparatória de Português. Prestou exames exigidos pela instituição para o seu ingresso, sendo aprovada com distinção. Até então, a escola era frequentada exclusivamente por pessoas do sexo masculino. Após ter sido autorizada pelo governo a frequentar a escola e

[...] a partir de 1891, com a participação de Julia Wanderley, as portas vão se abrir à presença feminina no Curso Normal o qual passará a ser promíscuo, consolidando o que de certa forma, já estava sendo idealizado politicamente (ARAUJO, 2013, p. 21740). 
Certamente as oportunidades educacionais que teve em Curitiba e os contatos com proeminentes intelectuais da época foram decisivos para a tomada de decisão. Após seu ingresso na escola normal, a procura feminina pela formação na escola aumentou, abrindo campo de trabalho especializado para as mulheres, tanto na capital, quanto em cidades promissoras do interior do estado. Mulheres passaram a buscar a profissionalização docente por meio da escola normal, mesmo que sujeitas a receber salários menores do que os dos professores homens (ALMEIDA, 2004; HAHNER, 2011).

E para as jovens que necessitavam trabalhar, a docência passou a ser vista como uma ocupação de prestígio e reconhecida socialmente (LOURO, 1997). No ano de 1882, o diretor de instrução pública da Província do Paraná, Moysés Marcondes, recomendou ao presidente da Província aceitar mulheres nas escolas normais. Além da aptidão delas para educar e cuidar das crianças,

[...] o magistério é uma carreira que oferece um modo de vida honesto que pode ser abraçado por muitas senhoras desamparadas e que servirá também de garantia à felicidade doméstica de famílias pobres (PARANÁ, 1882, p. 7).

Para estimular o ingresso das mulheres, ele sugeriu que a província criasse um "Pensionato Normal" na capital, com o intuito de receber moças pobres que desejassem ser professoras.

O cuidado maternal foi um dos aspectos que mais profundamente marcou a identidade de professoras primárias, e ainda marca. Isso fica evidente na vida de Julia Wanderley. Embora ela não tenha tido filhos seus, o cuidado com a educação e vida das crianças de outras famílias fazia parte de seu cotidiano. Agia com firmeza, mas com sensibilidade. Segundo Almeida (2004), considerando as especificidades da pesquisa, disseminou-se a ideia de relação do ensino com cuidados maternais. A figura feminina remetia à mãe. Sob os preceitos da moralidade, essas profissionais educavam as crianças com base em costumes e valores socialmente valorizados.

Louro (1997) argumenta que o processo de feminização do magistério esteve associado à ideia de que as mulheres, mesmo atuando como professoras, ainda poderiam cumprir com sua função de esposa e mãe. Assim, ao papel de professora foram incorporadas características maternais. A docência junto a crianças pequenas foi vista pela sociedade como um dom natural atribuído às mulheres.

Já que se entende que o casamento e a maternidade, tarefas femininas fundamentais, constituem a verdadeira carreira das mulheres, qualquer atividade profissional será considerada como um desvio dessas funções

RPGE- Revista on line de Política e Gestão Educacional, Araraquara, v. 25, n. 1, p. 149-167, jan./abr. $2021 . \quad$ e-ISSN:1519-9029 
sociais, a menos que possa ser representada de forma a se ajustar a elas. Em seu processo de feminização, o magistério precisa, pois, tomar de empréstimo atributos que são tradicionalmente associados às mulheres, como o amor, a sensibilidade, o cuidado etc. Para que se possa ser reconhecido como uma profissão admissível ou conveniente (LOURO, 1997, p. 96-97).

A docência nas escolas primárias do século XIX era uma ocupação predominantemente masculina, mas no século $\mathrm{XX}$ tornou-se tipicamente feminina. As mulheres se interessaram pelo campo de trabalho e benefícios advindos dessa profissão. (HAHNER, 2011). Um fato marcante, segundo o autor, foi a proibição da matrícula de homens na Escola Normal do Rio de Janeiro entre 1901 e 1907. Para as mulheres, nesse período, a docência

[...] significou o trânsito do invisível para a visibilidade e a realização de algo que não fosse o único e prestigiado serviço doméstico, como reduto privilegiado de feminilidade. O magistério era o trabalho intelectual e assalariado sem conotação pejorativa (ALMEIDA, 2004, s/p).

Assim como as escolas normais se modificavam, também se transformavam as escolas primárias. No final da década de 1910, casas escolares de cidades promissoras do interior do Estado do Paraná são remodeladas para Grupos Escolares, de acordo com o modelo paulista. As normalistas são cada vez mais requisitadas, sendo os grupos escolares as vitrines das regiões em que estavam inseridos, especialmente naquelas em que havia acesso pela ferrovia, gerando práticas modelares para as inúmeras escolas rurais multisseriadas existentes.

Em geral, essas normalistas somente lecionavam. A direção dos grupos escolares na maioria das vezes era ocupada por professores. Mas, gradativamente, elas também passaram a ocupar cargos na direção de escolas, a planejar e decidir sobre os rumos da educação, assumindo outras funções nos sistemas de ensino. Consolida-se um processo conhecido como feminização do magistério, que em particular no Paraná foi iniciada por meio da postura de Julia Wanderley para se matricular na Escola Normal de Curitiba.

\section{O legado de Julia Wanderley para as mulheres}

Para Julia Wanderley, a escola primária era fundamental ao desenvolvimento das crianças, capacitando-as para a vida em sociedade (SOUSA, 2013). Após sua formatura na Escola Normal, no final de 1892, a jovem paranaense iniciou sua carreira profissional como professora normalista na Escola Tiradentes, a qual dirigia. Assim como Julia, muitas outras normalistas foram assumindo a regência de escolas em cidades do interior. 
De acordo com o Regulamento da Instrução Pública do Estado do Paraná (1901), a organização didático-pedagógica adotava metodologia intuitiva, com:

[...] lição de coisas, conversação familiar, canto, primeiros ensaios de desenho, leitura, rudimentos de cálculo, recitação e exercícios manuais, alternando-se o ensino mental com exercício físicos, que constarão de jogos, brinquedos e movimentos ginásticos (PARANÁ, 1901, p. 95-96).

Durante sua atuação como diretora, em 1905, encaminhou ao Diretor Geral da Instrução Pública do Estado, Arthur Pedreira de Cerqueira, o relatório referente àquele ano letivo. Mais tarde, o relatório foi publicado no periódico A Escola ${ }^{11}$. Nele demonstrava o potencial da mulher para também atuar com as atividades administrativas inerentes à educação.

As transformações pelas quais passava a cidade de Curitiba e a educação exigiam atitudes compatíveis com o processo de modernização socioeducacional. O Estado concebia a Educação como um instrumento indispensável para desenvolver o espírito nacionalista, "sendo a escola capaz de conduzir a população nacional para a "civilização" (SOUSA, 2013, p. 88). Aqui, o aluno era formado para atender aos princípios nacionais. A educação era o caminho para atingir esse objetivo. Para Julia Wanderley a educação deveria promover

[...] o desenvolvimento físico, intelectual e moral da criança, é incontestavelmente a fonte principal do engrandecimento dos povos. A instrução esclarecendo-lhe o espírito e fornecendo-lhe a luz do saber, completa o seu aperfeiçoamento, colocando-a na altura dos mais elevados destinos. Em educar a criança, desenvolvendo-lhe as faculdades, formandolhe o caráter, aperfeiçoando-lhe o coração e ministrando-lhe conhecimento, consiste, pois, a grande obra do preceptor. A ele compete, não só pela palavra que instrui, como também pelo exemplo que moraliza, encaminhar os vacilantes passos daqueles que quem tudo espera a nossa sociedade (WANDERLEY, 1906, p. 18).

Para o Estado Republicano da época, a escola era vista "como um espaço de disciplinamento da força de trabalho" (SOUSA, 2013, p. 88). Com o capitalismo em ascensão, o modelo de Estado almejava, por meio da educação, formar o trabalhador para atuar no comércio e na indústria brasileira. A educadora, enquanto agente do Estado, internalizou na sua prática docente uma metodologia de ensino que prezava a formação

11 O periódico "A Escola" era organizado por alguns integrantes da elite curitibana, vinculados ao Clube Curitibano na época, entre o ano de 1906 e 1910. No início, o redator-chefe da revista era ninguém mais e ninguém menos que Sebastião Paraná, colega de Julia Wanderley no Colégio Curitibano. Posteriormente, o carioca Dario Vellozo passou a ocupar o cargo de Sebastião. Este visualizava a educação "como o principal caminho para "transformar" a sociedade ao desenvolvimento e o progresso" (SOUSA, 2013, p. 72).

RPGE- Revista on line de Política e Gestão Educacional, Araraquara, v. 25, n. 1, p. 149-167, jan./abr. $2021 . \quad$ e-ISSN:1519-9029 
intelectual das crianças, mas também a formação do caráter, para que adultos pudessem contribuir para o desenvolvimento da nação.

Em 1915, “d. Julia foi designada Membro do Conselho Superior do Ensino Primário e, em 27 de dezembro de 1915, foi também designada professora e diretora da Escola Intermediária" (NASCIMENTO; SOUSA, 2011, p. 273). No entanto, a diplomada não pôde usufruir por muito tempo das novas funções, visto que no dia 5 de abril de 1918, Julia Wanderley veio a óbito, aos 44 anos. No atestado de óbito consta como a causa da morte, neoplasma pelviano.

A morte de Julia Wanderley provocou inúmeras manifestações de carinho na sociedade curitibana. A fim de preservar a memória histórica da educadora, os paranaenses conceberam representações da figura mitificada em espaços públicos e privados da cidade, como por exemplo, o "busto da educadora, talhado por João Turin" (NASCIMENTO; SOUSA, 2011, p. 273) em bronze. O busto se encontra na Praça Santos Andrade, a mesma do prédio histórico da Universidade Federal do Paraná, numa clara alusão à sua significativa contribuição para a educação paranaense. A praça e o busto são espaços de memória da luta de paranaenses que, nas primeiras décadas do Século XX, não pouparam esforços para colocar em prática o projeto republicano para a educação, tanto na escola primária, quanto na Universidade.

\section{Considerações finais}

A institucionalização da Escola Normal em Curitiba, capital da província paranaense no século XIX, ocorreu em um momento em que as relações de trabalho se modificavam em função do processo de industrialização e urbanização que se iniciava. À medida em que as necessidades da escola primária se redimensionam, a escola normal também precisava se adequar ao seu tempo. Aceitar mulheres em seus bancos escolares era o começo de uma transformação que colocou as normalistas como protagonistas do processo educacional.

A pesquisa da trajetória de vida profissional dessa professora, no contexto histórico dos primeiros anos da República, evidencia novos atores sociais que se projetavam no período. Abrir a Escola Normal de Curitiba para as mulheres era uma ideia alguns anos antes, mas se torna realidade no ano de 1890, quando, sob algumas condições, Julia Wanderley ingressa naquele mundo que, até então, era exclusivamente masculino, rompendo com uma tradição e abrindo oportunidades a outras estudantes que a seguiram nos anos subsequentes.

Tendo uma vida pautada nos princípios da moralidade cristã e influenciada pelos ideais do movimento republicano, Julia Wanderley agiu pautada em princípios e convicções 
que norteavam as políticas educacionais da época. A figura feminina forte dedicou a vida à educação. Um século após sua morte, sua trajetória é rememorada na academia. A figura representativa continua presente na memória coletiva dos curitibanos e nos estabelecimentos públicos do estado do Paraná, isso devido a sua importância para a educação pública brasileira, principalmente no que concerne à inclusão de mulheres na função de professora.

\section{REFERÊNCIAS}

ALMEIDA, J. S. As professoras no século XX: as mulheres como educadoras da infância. In: III CONGRESSO BRASILEIRO DE HISTÓRIA DA EDUCAÇÃO (CBHE),3., 2004, Curitiba. Anais [...]. Curitiba, PR: PUC, 2004. Disponível em: http://www.sbhe.org.br/novo/congressos/cbhe3/Documentos/Coord/Eixo3/482.pdf. Acesso em: 11 nov. 2019.

ALMEIDA, J. S.; BOSCHETTI, V. R. Devotas e instruídas: a educação de meninas e mulheres no Brasil - fragmentos do passado histórico (1846/1930). Educação Unisinos, São Leopoldo, v. 16, n. 3, p. 225-233, 2012. Disponível em:

http://revistas.unisinos.br/index.php/educacao/article/view/edu.2012.163.04/0. Acesso em: 20 jul. 2020.

ARAUJO, S. A. C. Professora Julia Wanderley, uma mulher-mito (1874 - 1918). 2010. Dissertação (Mestrado) - Universidade Federal do Paraná, Curitiba, 2010. Disponível em: https://acervodigital.ufpr.br/handle/1884/25998. Acesso em: 30 jun. 2020.

ARAUJO, S. A. C. Julia Wanderley, precursora das professoras normalistas no Paraná: o ideal republicano e a invenção da mulher professora (1874 - 1918). In: CONGRESSO

NACIONAL DE EDUCAÇÃO (EDUCERE), 11., 2013, Curitiba. Anais [...]. Curitiba, PR: PUC, 2013. Disponível em: https://educere.bruc.com.br/CD2013/pdf/8714_4821.pdf. Acesso em: 30 jun. 2020.

BRASIL. Decreto n. 10 de 10 de abril de 1835. Decreto de criação da escola normal. Rio de Janeiro, 1835. Disponível em:

https://repositorio.ufsc.br/bitstream/handle/123456789/99970/1835_10_abril_Ato_n\%c2\%ba1 0_Cria_Escola_Normal.pdf?sequence=1\&isAllowed=y. Acesso em: 19 abr. 2020.

BRASIL. Lei n. 5.692 de 11 de agosto de 1971. Fixa Diretrizes e Bases para o ensino de $1^{\circ}$ e $2^{\circ}$ graus. Brasília, DF, 1971. Disponível em: http://www.planalto.gov.br/ccivil_03/leis/15692.htm. Acesso em: 18 abr. 2020.

CASTANHA, A. P. Escolas Normais no século XIX: um estudo comparativo. Revista HISTEDBR On-line, Campinas, n. 32, p. 17-36, 2008. Disponível em:

https://www.fe.unicamp.br/pf-fe/publicacao/5395/art02_32.pdf. Acesso em: 10 nov. 2019.

CORREIA, A. P. P. Escolas Normais: contribuição para a modernização do Estado do Paraná (1904 a 1927). Educar em Revista, Curitiba, n. 49, p. 245-273, 2013. Disponível em: https://www.scielo.br/pdf/er/n49/a14n49.pdf. Acesso em: 11 nov. 2019. 
GONDRA, J. A emergência da escola. São Paulo: Cortez, 2018.

HAHNER, J. E. Escolas mistas, escolas normais: a coeducação e a feminização do magistério no século XIX. Revista Estudos Feministas, Florianópolis, v. 19, n.n2, p. 467-474, 2011. Disponível em: https://www.scielo.br/pdf/ref/v19n2/v19n2a10.pdf. Acesso em: 16 nov. 2019.

LE GOFF, J. História e memória. Trad. Bernardo Leitão. Campinas, SP: Ed. UNICAMP, 1992.

LINHARES, S. Histórico do estado do Rio de Janeiro. Rio de Janeiro, 2020. Disponível em: http://www.inepac.rj.gov.br/application/assets/img/site/Historico_Estado.pdf. Acesso em: 03 maio 2020.

LOURO, G. L. Gênero, sexualidade e educação: uma perspectiva pós-estruturalista. Petrópolis, RJ: Vozes, 1997.

MARTINS, A. M. S. Breve reflexões sobre as primeiras escolas normais no contexto educacional brasileiro, no século XIX. Revista HISTEDBR On-line, Campinas, n. 35, p. 173-182, 2009. Disponível em:

https://periodicos.sbu.unicamp.br/ojs/index.php/histedbr/article/view/8639621/7189. Acesso em: 03 maio 2020.

MIGUEL, M. E. B.; MARTIN, S. D. (Org.). Coletânea da Documentação Educacional Paranaense no Período de 1854 a 1889. Brasília, DF: Instituto Nacional de Estudos e Pesquisas Educacionais Anísio Teixeira (Inep), 2004. Disponível em: http://www.gestaoescolar.diaadia.pr.gov.br/arquivos/File/museudaescola/coletanea_miguel.pd f. Acesso em: 23 nov. 2019.

MIGUEL, M. E. B. A escola normal no Paraná: Instituição formadora de professores e educadora do povo. In: CONGRESSO BRASILEIRO DE HISTÓRIA DA EDUCAÇÃO, 5. 2008, Aracaju. Anais [...]. Aracaju, SE, 2008. Disponível em:

http://sbhe.org.br/novo/congressos/cbhe5/pdf/9.pdf. Acesso em: 11 nov. 2019.

NASCIMENTO, M. I. M.; SOUSA, N. L. A Escola Normal de Curitiba e o pioneirismo de Julia Wanderley. Revista HISTEDBR On-line, Campinas, n. 42, p. 265-278, 2011. Disponível em:

https://periodicos.sbu.unicamp.br/ojs/index.php/histedbr/article/view/8639879. Acesso em: 11 nov. 2019.

NORA, P. Memória colectiva. In: LE GOFF, J.; CHARTIER, R.; REVEL, J. (Org.). A história nova. Coimbra: Almedina, 1990.

NÓVOA, A. (Org.). Profissão professor. Porto, Portugal: Porto Editora, 1995.

OLIVEIRA, M. C. M. Organização escolar no início do século XX: o caso do Paraná. Educar, Curitiba, n. 18, p. 143-155, 2001. Disponível em:

https://www.scielo.br/pdf/er/n18/n18a09.pdf. Acesso em: 16 nov. 2019.

PARANÁ. Decreto n. 93 de 11 de março de 1901. Regulamento para a instrução pública do Paraná. Curitiba, 1901. Disponível em: 
https://repositorio.ufsc.br/handle/123456789/123700\#: :text=Resumo\%3A,ensinos\%20prim \%C3\%A1rio\%2C\%20normal\%20e\%20secund\%C3\%A1rio. Acesso em: 5 jun. 2020.

PARANÁ. Lei n. 238, de 19 de abril de 1870. Institui uma Escola Normal para o ensino das pessoas de ambos os sexos que quiserem exercer o professorado da instrução elementar. Curitiba: DEAP, 1870. Disponível em:

http://www.gestaoescolar.diaadia.pr.gov.br/arquivos/File/museudaescola/coletanea_miguel.pd f. Acesso em: 19 abr. 2020.

PARANÁ, Relatório apresentado ao Governador em 1895. Curitiba, 1895. Disponível em: http://www.arquivopublico.pr.gov.br/arquivos/File/RelatoriosSecretarios/Ano_1895_MFN_6 38.pdf. Acesso em: 19 abr. 2020.

PARANÁ. Relatório apresentado ao Presidente da Província em 1882. Curitiba, 1882. Disponível em:

http://www.arquivopublico.pr.gov.br/arquivos/File/RelatoriosSecretarios/Ano1882MFN837.p df. Acesso em: 19 abr. 2020.

RANZI, S. M. F.; SILVA, M. C. Práticas disciplinares inauguradas com a República no ensino secundário paranaense. Pro-Posições, Campinas, v. 20, n. 1, p. 149-171, 2009.

Disponível em: https://www.scielo.br/pdf/pp/v20n1/v20n1a09.pdf. Acesso em: 03 maio 2020.

RIO DE JANEIRO. Decreto n. 1.331-A de 17 de fevereiro de 1854. Disponível em: https://www2.camara.leg.br/legin/fed/decret/1824-1899/decreto-1331-a-17-fevereiro-1854590146-publicacaooriginal-115292-pe.html. Acesso em: 03 maio 2020.

ROMANELLI, O. O. História da Educação no Brasil (1930/1973). 40. ed. Petrópolis, RJ: Vozes, 2014.

SOUSA, N. L. O Projeto Republicano para a educação no Paraná e o processo de (des)mistificação de Júlia Wanderley. 2013. 121 f. Dissertação (Mestrado) - Universidade Estadual de Ponta Grossa, Ponta Grossa, 2013. Disponível em:

https://tede2.uepg.br/jspui/handle/prefix/1350. Acesso em: 30 jun. 2020.

STENTZLER, M. M. (Org.). Conhecendo nossa história: a Escola Normal Professora Amasília de União da Vitória (PR). União da Vitória, PR: Kayagangue Ltda, 2018.

WANDERLEY, J. Relatório da escola Tiradentes de 1905. In: Revista Escola, 1906. 


\section{Como referenciar este artigo}

STENTZLER, M. M.; ARAÚJO, E. M. P.; MARQUES, L. P. A normalista Julia Wanderley: decisão, sensibilidade e necessidades sociais. Revista on line de Política e Gestão Educacional, Araraquara, v. 25, n. 1, p. 149-167, jan./abr. 2021. e-ISSN:1519-9029. DOI: https://doi.org/10.22633/rpge.v25i1.14017

Submetido em: 26/06/2020

Revisões requeridas: 10/09/2020

Aceito em: 20/11/2020

Publicado em: 02/01/2021 